\title{
Território, desenvolvimento endógeno e capital social em Putnam e Bourdieu
}

\author{
Antônio César Ortega' \\ Vitor Alberto Matos ${ }^{2}$
}

\begin{abstract}
Resumo
O estudo do desenvolvimento não deve se restringir a um único campo teórico. Estudos recentes sugerem a interação entre economia, história, sociologia e outras ciências humanas e sociais na perspectiva do território como construção social, apoiada na cooperação e reciprocidade, ainda que de natureza conflituosa. Muitas dessas perspectivas partem do princípio de que a construção de um território requer a existência de "capital social" elevado que possibilite um ambiente favorável ao engajamento visando ao desenvolvimento. Em Putnam, por exemplo, o capital social é um aspecto essencial para a apreensão do caráter endógeno do desenvolvimento. Crítico dessa perspectiva, Bourdieu, por sua vez, ressalta a necessidade de se introduzirem aspectos simbólicos para a compreensão do desenvolvimento como construção coletiva dos agentes locais. Apesar de certa proximidade entre suas formulações, sobretudo no tratamento teórico-interpretativo do capital social no que se refere à sua extensão, as divergências entre esses autores não são desprezíveis. Interpretações interdisciplinares, mesclando elementos simbólicos, culturais e econômicos são destacadas na análise de Bourdieu como elemento facilitador de diálogos envolvendo pensamentos e escolas diversificados, mas com profunda visão de interconexão.
\end{abstract}

Palavras-chave: Território. Desenvolvimento. Distritos industriais. Capital social.

I Doutor em Economia pela Universidade de Córdoba. Espanha, e professor associado do Instituto de Economia da Universidade Federal de Uberlândia. Minas Gerais, Brasil. É pesquisador elou consultor de organizações multilaterais (FAO/ONU). É autor de artigos publicados nas revistas Economía, Sociedad y Territorio (20/2), Segurança Alimentar e Nutricional (2012), Econômica (Niterói, 20I2), Revista de Economia e Sociologia Rural (Impresso, 201 I), entre outras. É autor de obras como Territórios deprimidos: os desafios das políticas de desenvolvimento rural (Alinea/Edufu, 2008) e Desenvolvimento sustentável: homem e natureza no cerrado mineiro" (Editora Roma, 2007),entre outros. E-mail: acortega@ufu.br.

2 Professor Titular aposentado do Instituto de Economia da Universidade Federal de Uberlândia, Minas Gerais, Brasil. Doutor em Economia de Empresas pela Fundação Getúlio Vargas, São Paulo, Brasil. É autor de artigos publicados na Revista Brasileira de Gestão e Desenvolvimento Regional (2009), na Revista Jurídica do Uniaraxá (2005) e na Revista de Ciência e Tecnologia, Recife (1998), entre outras.

E-mail:vamatos@netsite.com.br. 


\section{Introdução}

A literatura acadêmica que aborda o desenvolvimento territorial abrange um diversificado espectro, que se estende desde perspectivas centradas nos referenciais liberais, as quais partem do princípio da homogeneização ou horizontalização dos espaços, até formulações enfatizando a heterogeneidade em função das condiçôes econômicas, políticas, sociais e culturais concentradas espacialmente em determinada localidade ou região. Essa polissemia do conceito durante longo período contrapôs o intervencionismo estatal e as açôes autorreguladas do mercado.

Entre os anos 1970 e 1990 do século XX, frutos das tecnologias da informação e comunicação, surgiram argumentos associando sua difusão global ao desaparecimento das fronteiras e à perda de autonomia política e econômica dos governos nacionais e locais, traduzidos segundo Haesbaert (2006) pela expressão "fim dos territórios". Nas abordagens propostas por organismos mundiais multilaterais, o desenvolvimento territorial é visto como "reação autônoma" (PECQUEUR, 1987), em que condiçóes virtuosas, a partir das potencialidades internas aos territórios, promoveriam endogenamente o desenvolvimento. Contrariamente, Pecqueur (1987), Boyer (2001), Benko (2002), Reis (2002), entre outros, que ressaltam a heterogeneidade, mesmo em tempos de globalização, sugeriam a capacidade de as iniciativas territoriais gerarem formas virtuosas de inserção produtiva nos circuitos globais. Em outros termos, entende-se que o "território é nexo, ligadura e junção de confluências e conflitualidades de projetos de sujeitos sócio-políticos" (BRANDÃO, 2007, p. 53).

Essa perspectiva que reconhece a heterogeneidade territorial supóe uma abordagem interdisciplinar que associe economia, particularmente a institucional, história, sociologia e outras ciências humanas e sociais ${ }^{3}$. A abordagem institucional seria uma "tentativa de entender as possibilidades para o desenvolvimento endógeno de economias de dinâmicas territorializadas, assentadas na cooperação, em aprendizagem, conhecimentos tácitos e culturas técnicas

3 De acordo com Muls (2008, p. 3), na perspectiva territorial podemos identificar aspectos ligados a instituições formais (governos, sindicatos, representações de interesse) e aspectos associados a instituições informais, como cooperação, confiança, reciprocidade, altruísmo, todos destinados à regulação do comportamento das pessoas em suas interações sociais. 
específicas e em inter-relaçôes sinérgicas" (REIS, 2002, p. 116). A historicidade resultaria de um processo de causação através do qual as açôes individuais (regularidades) definem pontos de vista (modelos mentais de percepçôes individuais) sobre a realidade, e as instituiçôes sociais, a cultura e as rotinas atuam na seleção e compreensão das informaçôes percebidas ${ }^{4}$. A seleção de um determinado aspecto implica alteração e reforço daquela percepçáo, demonstrando que as instituiçôes, ao provocarem mudanças de atitudes e ações (segundo rupturas e regularidades) atuam como agentes transportadores dos elementos fundamentais do futuro e obrigam os atores a estarem sempre avaliando os comportamentos rotineiros atuais e a necessidade de suas alteraçóes.

Embora relevantes, na perspectiva territorial as açóes do Estado e do mercado devem subsidiar a elaboraçáo de estratégias construídas a partir dos territórios, pelas suas instituiçóes e unidades organizacionais. Segundo Garofoli (1993, p. 71), "somente a nível local podem, de fato, ser individualizadas as necessidades específicas de reforço e a consolidação dos sistemas territoriais para a economia extensiva e podem ser predispostas políticas de intervençôes coerentes para eliminar os pontos fracos do processo de industrialização", deixando claro tanto seu caráter multidisciplinar quanto sua orientação à identificação dos vários aspectos e esferas do espaço social.

Vários estudos, sobretudo entre os anos 1970 e 1980, procuraram não só explicar a crise capitalista daquele período, como também salientar a relação entre as dotaçóes das várias espécies de capital e seus desempenhos em termos de crescimento econômico. Entre eles, alguns salientavam trabalhos iniciais de Marshall relacionados ao ambiente industrial da Inglaterra do século XIX, em que se identificavam condiçôes endógenas favoráveis como responsáveis pelo surgimento e pela consolidação de aglomeraçôes" ${ }^{5}$ uma vez que "provocariam efeitos positivos aos concorrentes [...] que criam, como explicava Marshall $(1919)^{6}$, certa atmosfera, não mensurável, que estabelece um princípio de organização não mercantil entre as empresas" (BENKO, 2002, p. 53).

4 É consensual no institucionalismo que as instituições moldam a política e são moldadas pela história.

5 Inicialmente Marshall utiliza o termo "indústria localizada" para definir indústrias concentradas em determinadas localidades. $O$ "distrito industrial" a que ele se refere trata-se de uma localização específica nas grandes cidades (MARSHALL, 1983, p. 235). No trabalho em parceria com sua esposa o termo salientará diversas vantagens difundidas no interior dos territórios onde se localizam. Aqui, salvo melhor entendimento, o termo adquire a significação atual.

6 A citação constante do texto de Benko (2002) se refere ao texto original dos "Princípios de Economia" de Marshall, que estamos referenciando a partir da publicação brasileira na coleção "Os Economistas" Marshall (1983) 
Esse ambiente favorável ao engajamento de forças orientadas para o desenvolvimento territorial, a partir da década de 1990, foi identificado como o aspecto fundamental ao surgimento do conceito de "capital social", na tentativa de explicar as assimetrias de desempenho entre várias formaçóes sociais. Embora alvo de críticas por sua amplitude e por exigir aprofundamento teórico, ele é responsável, conforme argumenta Putnam (2006) de forma pioneira, por ser elemento essencial do caráter endógeno do desenvolvimento, demonstrando que "os estoques de capital social, como confiança, normas e sistemas de participação tendem a ser cumulativos e a reforçar-se mutuamente" (PUTNAM, 2006, p. 186). Nessa perspectiva, um desenvolvimento virtuoso resultaria de altos índices de cooperação, confiança e reciprocidade, construídos a partir da capacidade da sociedade em se organizar visando ao bem-estar coletivo.

A elevada difusão do uso do conceito de capital social fez surgir uma grande diversidade de enfoques analíticos, principalmente no âmbito da Nova Sociologia Econômica, enfatizando açôes facilitadoras da coordenação e comunicação coletivas (MARQUES, 2003, p. 25). Assim, o conceito tornou-se alvo de fortes questionamentos, resultantes da polissemia ${ }^{7}$ de suas formulaçóes nos estudos sobre desenvolvimento.

Entretanto, não é comum nas análises sobre o desenvolvimento territorial a ênfase nos aspectos culturais e simbólicos, principalmente naqueles ligados ao poder, ao prestígio e à reputaçáo, fundamentais para o interconhecimento e o inter-reconhecimento essenciais ao "amalgamento grupal", do qual surgem a cooperação, a confiança e a reciprocidade, bem como a utilização de elementos próprios da sociologia bourdieuziana para o entendimento e aprimoramento das contribuiçôes assentadas no desenvolvimento territorial.

Sendo assim, este trabalho visa destacar as diferenças do conceito de capital social em Putnam e em Bourdieu, além de verificar sua pertinência nas análises do desenvolvimento. Também pretende verificar a possibilidade de se introduzirem aspectos simbólicos e culturais, retirados de Bourdieu, relacionados ao capital social, em que o desenvolvimento territorial seja construção

7 De acordo com Moyano Estrada (1999, p. 9), os diversos autores ao utilizá-lo "lo han hecho sin prestar mucha atención ni a su historia intelectual, ni a su status ontológico, sino simplemente enfatizando aquellas dimensiones del mismo que les son más útiles para sus particulares propósitos investigadores". 
coletiva local ${ }^{8}$. Nossa hipótese é a de que os processos de desenvolvimento, na perspectiva territorial, devem envolver pactos sociais que reconheçam as junçôes, ligaçóes e confluências sem excluir os conflitos de interesse envolvidos, originários de lutas por manter ou ampliar posiçóes ocupadas na estrutura de distribuição de posiçôes de um campo social específico, porém buscando construir condiçóes propícias para a sua concertação.

Para tanto, este artigo está elaborado em quatro seçôes, incluindo-se esta introdução. A segunda seção faz uma releitura sobre os distritos industriais; a terceira apresenta uma análise das visôes de capital social no entendimento de Putnam e Bourdieu, buscando destacar elementos fundamentais que podem compor uma abordagem unificada, destinada a integrar o simbólico-cultural às análises sobre desenvolvimento territorial; e a quarta, por fim, apresenta as consideraçóes finais sobre a possibilidade pretendida.

\section{A emergência das experiências locais}

O desenvolvimento, como processo de inclusão social que busca melhorar as condiçóes de existência, ou seja, proporcionar maior acesso a bens materiais e culturais, é fruto de um longo período de lutas sociais ocorridas entre o final do século XIX e início do século XX9 . A tentativa capitalista de superar tais dificuldades e, ao mesmo tempo, de reagir à emergência de sistemas alternativos foi fundamental para que no Ocidente o Estado assumisse açóes de caráter intervencionista em busca de taxas mais elevadas de crescimento. Entretanto, a crise do Estado do Bem-Estar levou à adoção de políticas mais ortodoxas de açáo estatal das quais resultou drástica redução da presença do Estado na Economia. No entanto, seja do lado das agências e organismos multilaterais, seja a partir dos círculos acadêmicos, foram sendo gestadas, nas últimas décadas, recomendaçóes visando à descentralização das políticas públicas. De outro lado, as recomendaçôes "de cima para baixo" passavam a ser

8 Na tentativa de contribuir analiticamente com o estabelecimento de condições mais próximas das realidades comunitárias de largos espaços da sociedade brasileira, estamos conscientes de que, para aqueles territórios denominados por Ortega (2008) como "deprimidos", ainda será necessário verificar a sua capacidade de criar capital social.

9 Com o fim da Segunda Guerra Mundial, o mundo desperta para a criação de um novo ambiente fundado na busca por superar as crises anteriores. Nesse período surgem a Organização das Nações Unidas e suas agências de desenvolvimento, organismos multilaterais cujo objetivo principal era a busca por maior estabilidade entre as nações e o apoio ao desenvolvimento. 
acompanhadas por pressóes originárias de vários segmentos sociais até então excluídos dos processos decisórios, visando sua inclusão no processo decisório. Essas açôes vindas de "baixo para cima" eram fruto do interesse dos diferentes segmentos sociais e enfatizavam o desenvolvimento local, ou seja, buscavam processos descentralizados de construção do desenvolvimento ${ }^{10}$.

Contrariando argumentos sobre a capacidade e as chances de as pequenas empresas enfrentarem a competiçáo interna e internacional das grandes organizaçóes produtivas, os "distritos industriais" italianos - e de outras experiências europeias com resultados semelhantes àqueles - são exemplos bem-sucedidos de processos de desenvolvimento em que

uma miríade de pequenas unidades de produção, aparentemente desfavorecida em termos de estruturas de comercialização, de escala produtiva, de acesso ao crédito e de intervenções nos mercados estrangeiros, conseguiu captar uma parte crescente do mercado (interno e internacional), obtendo maiores lucros e criando empregos" (BECATTINI, 2002 p. 46).

Relativamente ao caso latino-americano, a temática territorial despertou grande interesse por enfatizar as especificidades das demandas dos diversos segmentos sociais que, no contexto de redemocratização por que passava o continente, exigiam experiências de maior participação populacional, visando a construir de forma pactuada propostas envolvendo as diversidades existentes nesses territórios. Segundo Ortega (2008, p. 40), na sua grande maioria, esses movimentos visam o "combate à pobreza e à exclusão, e vêm constituindo-se em alternativas para a inclusão social e inserção competitiva dos territórios nos circuitos regionais, nacionais e internacionais mais dinâmicos".

A experiência dos "distritos industriais"11 italianos, referência de vários estudiosos dos processos de desenvolvimento, revelou-se importante tanto por enfatizar a capacidade organizativa dos agentes locais em promover um período virtuoso de desenvolvimento, quanto por deixar evidente, nesse período, uma

10 Esse longo processo evolutivo do surgimento das ideias de desenvolvimento local e de suas condições é didática e extensivamente tratado em Ortega (2008, p. 21-50).

II 0 conceito de "Distrito Industrial" surge a partir de Marshall, em suas publicações de juventude, quando se refere a certos tipos de produção que permitiam duas formas eficientes: uma com base em grandes unidades. internamente integradas verticalmente, e outra centrada em numerosas fábricas de pequenas dimensões. especializadas nas diversas fases de um único processo produtivo, todas concentradas em uma ou várias localidades (BECATTINI, 2002b, p. 46). 
Itália cujos resultados positivos no comércio internacional eram decorrentes principalmente dos bens imaginados e criados naqueles distritos em um momento no qual a produção em massa dava mostras de baixa atratividade.

De acordo com Becattini (1990), apesar da reversão teórica operada nos "Princípios de Economia", Marshall ${ }^{12}$, ao afirmar a flexibilidade tanto das fronteiras entre as firmas quanto de suas inter-relaçóes e seus comportamentos de cooperação e reciprocidade, estaria se referindo às condiçóes específicas, presentes no ambiente dos pequenos estabelecimentos, e fundamentais ao seu sucesso. Essa afirmação também reforçava observaçôes de Piore e Sabel (1984), que enfatizavam a relevância da flexibilidade das fronteiras para o atendimento diferenciado e diversificado a demandas cada vez mais singulares, para a aprendizagem compartilhada, para a troca de experiências e para o desenvolvimento conjunto de produtos e processos, possibilitando o "amalgamento grupal" entre empresas devido às açôes de interconhecimento e inter-reconhecimento.

Entre as décadas de 1970 e 1980, ao mesmo tempo em que o sistema de produçáo baseado em grandes unidades sofre profundas transformaçóes nas principais economias avançadas, também se desenvolve, segundo Garofoli (1993, p. 54), "[...] o maior modelo das microestruturas (a pequena empresa, a cidade de pequena-média dimensão etc.)", o que, em alguns países, possibilitou o ressurgimento do sistema das pequenas empresas, devido à sua grande flexibilidade e capacidade de adaptaçáo. No caso italiano, vivia-se um período de desenvolvimento marcado pelo aparecimento de vários "distritos industriais", que vinham demonstrando grande vigor e apresentando resultados positivos inclusive no comércio internacional, fruto dos "bens fabricados nesses distritos".

Dizendo melhor, pequenas empresas e territórios onde emergissem a inovação, a flexibilidade e o desenvolvimento de redes de relacionamentos cooperativos, compartilhados, participativos e recíprocos seriam "espaços ganhadores", no sentido de Benko e Lipietz (1992) - locus de desenvolvimento capitalista com resultados positivos ${ }^{13}$. Portanto, o desempenho das pequenas

12 As referências de Becattini se baseiam nos textos marshallianos escritos por volta de 1870 e reunidos por J. Whitaker (1975). Ver para maiores detalhes, ver Becattini (2004)

13 Ao ressaltarmos esse desempenho regional superior (não somente na Itália, mas também no Vale do Silício Califórnia, na Rota 128 -, Massachusetts e as tecnópolis - Europa e Japão), nosso objetivo não é afirmar a 
empresas contradizia tanto a ideia de que o "avanço econômico associa-se a grandes empresas", quanto a norma de que "o pequeno empreendimento tem função subsidiária e complementar na economia”, ou seja, essas experiências confirmavam que os pequenos negócios constituíam uma alternativa produtiva viável que implicava geração de renda e emprego.

O sucesso da experiência italiana fez emergir, no debate acadêmico e nas propostas de estudo das áreas industrial e regional da economia, a questáo relacionada aos elementos que caracterizariam essas experiências virtuosas, fosse no aspecto das organizaçóes (sociais ou produtivas), fosse no tocante às instituiçóes presentes. A presença generalizada de pequenas empresas foi determinante para que os principais organismos multilaterais mundiais passassem a recomendar o enfoque territorial como estratégia alternativa de desenvolvimento. Coincidindo com o momento em que as políticas neoliberais recomendavam o "Estado mínimo", aquele modelo de desenvolvimento permitia que se transferissem para o ambiente local as responsabilidades do planejamento do desenvolvimento. A profundidade dos compromissos e da aprendizagem desenvolvidos nas relaçóes das empresas entre si, dessas com a mão de obra especializada e entre os diversos segmentos dessa mão de obra em determinado território ${ }^{14}$ criaria um ambiente simbiótico, ou estado de espírito, baseado no sentimento de pertencimento à comunidade local - uma fusão harmoniosa entre o individualismo e o sentido comunitário.

\section{Desenvolvimento e capital social}

A experiência dos arranjos socioprodutivos locais, constituídos a partir das capacidades endógenas dos próprios agentes, tem como novidade "a recuperação vigorosa das noçóes de intertemporalidade e de irreversibilidade da trajetória do desenvolvimento econômico" (AMARAL FILHO, 2001, p. 267), aspectos de caráter schumpeteriano (SCHMITZ, 1997, p. 173) que

derrocada das grandes empresas no cenário produtivo do capitalismo, uma vez que a flexibilidade também atingiu essas unidades. Muito menos se pretende eliminar a atratividade das grandes cidades às populações $e$ aos investimentos, ainda fortemente evidentes.

14 De acordo com Garofoli (1993), a redistribuição territorial das atividades produtivas naquele período resultou dos seguintes fenômenos: despopulação produtiva, desenvolvimento não metropolitano, desindustrialização, deslocalização e descentralização territorial, desenvolvimento demográfico periférico, desconcentração produtiva, formação e desenvolvimento de sistemas produtivos locais. 
podem ser traduzidos por "eficiência coletiva", ou "vantagens derivadas de economias externas locais e ação conjunta".

Os diversos estudos ${ }^{15}$ envolvendo "distritos industriais", sobretudo os de cunho multidisciplinar e ligados às abordagens institucionalistas e evolucionistas, foram pródigos na identificação de seus determinantes: alguns presos ao perfil e à estrutura do sistema produtivo local, outros às numerosas e intensas relações desenvolvidas com os mercados finais domésticos e internacionais, outros ainda aos fortes laços familiares presentes nessas aglomeraçóes, e, por fim, alguns salientando os relacionamentos internos ligados a fatores históricos, sociais e culturais enraizados ou sedimentados na comunidade e nas instituiçóes existentes. Com relação a esses últimos, ou seja, ao "amalgamento grupal" e à valorização do capital social - representado por redes de relacionamentos entre sujeitos individuais e coletivos, visando a sedimentar um coletivo social, essencial para o desenvolvimento e a consolidação da cooperação e da confiança entre todos, bem como a ajudar no aprofundamento das economias externas -, deve ser ressaltada tanto sua proeminência na literatura sobre os "distritos industriais", e demais denominaçóes dessas formaçóes socioprodutivas, como sua emergência como conceito fundamental à consolidação de uma economia diferenciada, mais solidária e humana ${ }^{16}$.

\section{O capital social na abordagem de Robert D. Putnam}

A análise de Robert D. Putnam sobre o caso italiano, apresentada em seu trabalho pioneiro ${ }^{17}$ (PUTNAM, 2006), sustenta como argumento determinante daquele sucesso e de sua abordagem do capital social o fato de que naquelas regióes em que se pudesse identificar bom funcionamento do sistema econômico, e ao mesmo tempo níveis elevados de integração política, tais resultados certamente decorreriam de uma bem-sucedida acumulação de capital social.

15 Na impossibilidade de realizarmos uma análise sobre todas as contribuições envolvendo esses aspectos, nos limitamos, na seção anterior, aos trabalhos referentes à realidade da Terceira Itália e, dentre as inúmeras contribuições sobre essa região, aos trabalhos dos italianos: Arnaldo Bagnasco, Giacomo Becattini e Gioacchino Garofoli, que aprofundam cada um dos aspectos salientados.

16 Entretanto, a coexistência entre concorrência e cooperação, a troca de informações, seja nas empresas ou nos relacionamentos informais entre atores visando a atingir objetivos propostos, a melhorar o ambiente social $e$ a criar uma democracia mais vital, também devem ser consideradas de grande relevância.

17 Estamos nos referindo ao seu estudo de 1993: "Comunidade e Democracia: a experiência da Itália moderna", em que encontramos as ideias mais relevantes sobre o conceito de capital social. 
Melhor dizendo, o que Putnam pretende mostrar - e que se revela como sua questáo de fundo no entendimento do conceito de capital social, a respeito dos diferenciais de desempenho entre governos democráticos de países com dotaçôes similares de recursos - é uma proposta investigativa traduzida em sua questâo inicial do primeiro capítulo: "Por que alguns governos democráticos têm bom desempenho e outros náo?" (PUTNAM, 2006, p. 19). Segundo Ortega (2008), o pioneirismo desse autor estaria na sua tentativa de integrar os aspectos sociais e institucionais resumidos na noçáo de capital social. Nesta integração, o conceito "diz respeito a características da organização social, como confiança, normas e sistemas que contribuem para aumentar a eficiência da sociedade, facilitando as açóes coordenadas" (PUTNAM, 2006, p. 177).

Para explicar aquelas assimetrias de desempenho destacadas, ele se concentra nas "condiçôes necessárias ao desenvolvimento de instituiçôes fortes, responsáveis e eficazes" (PUTNAM, 2006,, p. 22), todas representativas de uma economia próspera. Segundo Sí́siänen (2000, p. 1), o conceito de capital social proposto por Putnam possui três componentes essenciais: a) normas e obrigaçôes morais; b) valores sociais, especialmente a confiança; c) redes sociais, destacadamente as associaçôes voluntárias.

A afirmação de que "a cooperação voluntária é mais fácil numa comunidade que tenha herdado um bom estoque de capital social sob a forma de regras de reciprocidade e sistemas de participação cívica” (PUTNAM, 2006, p. 177) ${ }^{18}$ não exclui, mas, ao contrário, sugere que a "incerteza quanto à reputação" (ou história de vida) "e o risco de descumprimento são minimizados por normas rígidas e por uma densa teia de comportamentos recíprocos" (PUTNAM, 2006, p. 178). Em outros termos, de um lado, a hereditariedade e/ou a reputação serviriam como fatores garantidores dos comportamentos cooperativos, por diminuírem as possibilidades de descumprimento; e de outro, a intensidade dos comportamentos recíprocos e a presença de formas coercitivas severas em suas penas facilitariam a confiabilidade e a cooperação recíprocas ${ }^{19}$.

18 Embora muitos autores se refiram a Coleman (1990) e este, por sua vez, atribua a Loury (1977) a introdução do conceito, é importante ressaltar que Marshall (1983, p. 212) já salientava essas características herdadas, destacando enfaticamente o caráter reciproco dos comportamentos sociais.

19 Em outras palauras, o que se afirma é que as instituições são fundamentais por fazerem emergir regularidades comportamentais (interconhecimento e inter-reconhecimento) que facilitam mecanismos de busca por beneficios mútuos (entendimento que aproxima Putnam, assim como Bourdieu, de uma visão instrumentalista). 
Em suma, em algumas formaçóes sociais, surgem fatores ou mecanismos capazes de criar elevados níveis de confiabilidade entre seus membros, ao mesmo tempo em que "a cadeia de relaçóes sociais" difunde a consciência recíproca desse sentimento, ou seja, na confiabilidade dos outros em cumprir compromissos é que se sustentam os comportamentos de reciprocidade. Essas afirmaçôes de modo algum sugerem ausência de mecanismos formais direcionados a coibir tentativas oportunistas.

Portanto, o capital social revelaria o fundamento das democracias plenas em vitalidade comunitária, uma vez que as açôes desenvolvidas, coletiva e voluntariamente, levariam ao enraizamento do capital social no interior delas ${ }^{20}$. Segundo Frey (2003, p. 176), tais fundamentos, presentes no território da denominada Terceira Itália, a um só tempo garantiram as características democráticas daquela sociedade e orientaram o desempenho dos governos e de suas instituiçóes. Dizendo mais explicitamente, Putnam associaria o capital social às características especificamente institucionais, como as redes, as normas e a confiança, todas elas facilitadoras da coordenação e da cooperação e, adicionalmente, instituídas pela vontade ou disponibilidade, e não pela violência material ou simbólica decorrente da autoridade hierárquica.

Ao tratar a confiança, Putnam se refere a uma confiança generalizada ou social, "fruto de duas fontes conexas: as regras de reciprocidade e os sistemas de participação cívica" (PUTNAM, 2006, p. 181), através dos quais os comportamentos positivos disseminam-se pelos demais interlocutores por meio do desenvolvimento de relaçóes comunitárias. Segundo ele, tais fatores explicariam a criação da confiança generalizada a partir das regras de reciprocidade e do associativismo voluntário; e, ao mesmo tempo, essa reciprocidade e esse associativismo produziriam mais confiança. Nesse sentido, quanto maior fosse a utilização do capital social, maior seria o seu crescimento e o aparecimento de círculos virtuosos de cumulatividade do capital social promotores do equilíbrio social, demonstrando elevados níveis de cooperação, confiança em expansão e fortes níveis de reciprocidade e de atividade cívica (PUTNAM, 2006, p. 181-83).

De acordo com Siísiänen (2000, p. 5), as açôes realizadas coletivamente marcam a transposiçáo dos relacionamentos orientados pela familiaridade

20 No caso italiano, estes pilares seriam: uma alta densidade de associações (caráter institucional local) e a existência de relações sociais baseadas na reciprocidade (caráter social e cultural historicamente desenvolvido). 
para contextos dominados pela contingência, pela complexidade e pela incerteza; o que, em termos keynesianos, significaria afirmar que a confiança seria necessária quando as expectativas e os relacionamentos familiares fossem insuficientes na previsão e antecipação das reaçóes individuais ou coletivas nas interaçôes sociais. Dessa forma, "normas como essas, que fortalecem a confiança social, vingam porque reduzem os custos de transação e facilitam a cooperação" (PUTNAM, 2006, p. 181).

Sua análise do conceito de associaçôes voluntárias - fator essencial presente na sociedade civil e fonte primordial da confiança - é a afirmação da "mais importante forma de interaçâo horizontal e de reciprocidade". Portanto, os sistemas de participação cívica seriam uma forma essencial do capital social e influenciariam a interação social e a cooperação entre os agentes, exercendo um poderoso efeito por aumentarem os custos potenciais para os transgressores; promoverem sólidas regras de reciprocidade; facilitarem a comunicação e tornarem possível o fluxo de informaçóes sobre a confiabilidade dos indivíduos e, por fim, corporificarem o êxito alcançado em colaboraçóes anteriores, logo, alicerçarem futuras interaçóes (PUTNAM, 2006, p. 183). Nesse aspecto, Putnam se refere à historicidade com base na ideia de "path dependence", uma vez que "constituem um repertório histórico de formas de colaboração que, por terem se revelado eficazes no passado, podem ser aproveitadas pelos cidadáos para lidar com novos problemas de ação coletiva” (PUTNAM, 2006, p. 184).

Essas associaçóes voluntárias também contribuiriam muito para a resolução de problemas administrativos e a redução da complexidade do ambiente, atuando como geradoras da confiança. Tais afirmaçóes, para muitos críticos dos trabalhos de Putnam, nada mais fazem do que reduzir a sociedade civil unicamente às associaçôes voluntárias ${ }^{21}$.

Em suma, a vida social baseada em um estoque de confiança e reciprocidade - ou em um estoque de capital social - necessita de organizaçóes sociais voltadas para o estabelecimento de normas e padróes comportamentais comuns fundamentais para a promoçáo da confiança social e interpessoal, reforçando-as contínua e crescentemente. Entretanto, essa argumentaçáo prima por enfatizar unicamente os fatores culturais como os principais

21 Ver essas afirmações em Siisiänen (2000, p. 6), citando Tenbruch e Ruoff (1983); Richter (1985); Siísiänen (1986 e 1998) 
determinantes da confiança e do capital social, uma vez que, segundo Putnam, tais fatores explicam as desigualdades de desempenho econômico e político. Consequentemente, quanto maior a incidência ou a intensidade dos relacionamentos horizontais (pessoa a pessoa), ou quanto maior a intensidade dos relacionamentos sociais, desde que se considerem as especificidades locais e se valorize a história de vivência comunitária ou sua necessidade, mais se efetivariam os comportamentos de engajamento individual e coletivo criadores de capital social (PUTNAM, 2006, p. 185).

Entretanto, a teoria do capital social de Putnam enfrenta o grande problema de excluir o conflito e as organizaçóes conflituosas de suas análises e dos pilares do consenso, ignorando ou obscurecendo um elemento primordial para o entendimento da emergência da confiabilidade, sobretudo em sociedades cujas estruturas são erigidas a partir de interesses pactuados.

\section{O capital social na ótica de Pierre Bourdieu}

Em Bourdieu identifica-se uma construção teórica centrada na concepção relacional e sistêmica do social, "uma racionalidade econômica como encontro de disposiçôes socialmente construídas (em um campo) e as estruturas, elas mesmas socialmente construídas, desse campo" (BOURDIEU, 2005, p. 23). Neste autor, e em oposiçáo à análise de Putnam, o capital social assume uma conotação que ressalta enfaticamente o conflito, por estar "associado às suas idéias teóricas sobre classe". Ao identificar três dimensóes do capital em geral ele "associa cada uma delas, de maneira específica, às classes (capital econômico, cultural e social) [...] três recursos que se tornam socialmente efetivos e sua propriedade legitimada pela mediação do capital simbólico" (BOURDIEU, 1985, p. 243). O seu argumento enfático exprime-se na interpretação mais realista do mundo das "contingências e urgências cotidianas", ao referenciar tal conceito aos conflitos relacionados ao poder (ou influência) - relaçôes sociais que amplificam a facilidade de um agente atingir seus interesses e que pode se tornar um recurso das disputas sociais em diferentes arenas e campos (do social) $)^{22}$.

22 Ver para maiores detalhes seu texto de 1985, "The forms of capital", sobretudo nas páginas 249-52, em que o autor apresenta sua visão de capital social. Na coletânea Escritos de Educação, organizada por Maria Alice Nogueira e Afrânio Catani (BOURDIEU, 20 I0, p. 67-9), encontramos sua versão inicial traduzida de Actes de la recherche em sciences socioales (n. 3I, p. 2-3), de 1980 
Para Luïc Wacquant, "toda a obra de Bourdieu pode ser interpretada como uma antropologia materialista da contribuição específica que diversas formas de violência simbólica fazem à reprodução e transformação das estruturas de dominação" (BOURDIEU; WACQUANT, 2008, p. 39). Dizendo melhor, os conceitos de Bourdieu ${ }^{23}$ tentam afirmar que "os coletivos sociais", de maneira geral, nada mais são do que instrumentos destinados à imposição de uma visão de mundo favorável a interesses particulares; logo, o conflito e a dominação parecem sempre presentes em suas análises. Dessa forma, a trajetória de suas concepçóes estaria inserida em uma construção sociológica do conflito e na tradiçáo estruturalista de uma sociologia de integração e funcionalismo (SIÍSIÄNEN, 2000, p. 10).

A constância da ideia de conflito em sua obra traduz sua percepção real do cotidiano enfrentado pelos agentes sociais. Sendo concisos nos exemplos, verificamos que ao criar o conceito de campo, ele o apresenta tanto como um campo de forças, resultantes da posiçáo ocupada pelos agentes na estrutura social e que lhes garante determinado poder de influência nesse subespaço específico, quanto como "um campo de lutas destinadas a conservar ou a transformar o campo de forças, um campo de ação socialmente construído onde se afrontam agentes dotados de recursos diferentes" - os tipos específicos de capital (BOURDIEU, 2005, p. 24, 33). Da mesma forma, ao resumir suas ideias sobre habitus e conflito ${ }^{24}$, ele apresenta o primeiro como conjunto de disposições e formas comportamentais adquiridas pelas pessoas ao atuarem em sociedade, refletindo suas diferentes posiçóes dentro dela, ou seja, como participantes de seu próprio modus de se produzir.

Em síntese, vê-se claramente que o habitus também é mudança, ou decorre de situações recorrentes na sociedade e que implicam modificaçôes de atitudes e comportamentos, o que seria o mesmo que admitir que o conflito esteja sempre presente na sociedade. Nessa concepção, visualizamos uma

23 Sem a pretensão de qualquer tipo de conclusão, mas apenas tentando apresentar um resumo comparativo, diríamos que se as ideias de Putnam sobre o capital social ressaltam os valores coletivos e a integração social, o aporte de Bourdieu se constrói em torno do ponto de vista de um ator engajado em lutas por interesses sempre conflitivos (SIÍSIÄNEN, 2000, p. 10).

24 Sua visão do social antepõe os agentes e as estruturas: os primeiros como criadores do campo, uma vez que este só se concretiza nos agentes que se encontram em seu interior e cujas atuações sempre são passiveis de gerar alterações em sua estrutura; e os segundos como forma hierarquizada, desigual e conflituosa da distribuição de recursos e poderes (materiais e simbólicos) de cada um dos agentes participantes. 
estrutura social hierarquizada de prestígio e poder (ao mesmo tempo fruto de relaçôes econômicas, como salário e renda, de relaçóes simbólicas, como o status, e culturais, como grau de escolaridade) entre os indivíduos (SETTON, 2008, p. 48).

Essa assimetria de posiçôes é determinada pelo volume e pela estrutura (composição ou distribuição) de um ou mais capitais, nas suas diferentes representaçóes: a financeira, a cultural, a tecnológica, a jurídica, a organizacional e informacional, a comercial, a simbólica e a social que cada um dos agentes adquiriu ou incorporou durante sua história no interior do campo.

Dessa forma, a dinâmica das posiçóes naquela estrutura resulta do peso (ou do poder) que os agentes "dominantes" possuem sobre os agentes "dominados", muito mais do que de mecanismos diretos de pressão que possam controlar (preços, imposiçôes e retaliaçôes, entre outros) ${ }^{25}$. Portanto, a própria estrutura imprime regularidades mais duradouras, ou seja, "as regras do jogo", ou mesmo "os limites do próprio jogo", o que faz com que se estabeleça um ambiente em que, "apenas pela sua presença”, em função da possibilidade de seus comportamentos estratégicos - os demais agentes, reconhecendo sua posição na estrutura, preferem a estabilidade ao confronto -, provoquem modificaçôes no ambiente concorrencial (como as mudanças de posiçóes na estrutura) modificando, assim, os espaços de movimentação possíveis.

Em busca de uma nova linguagem que expressasse sua visão da ação de cunho interdisciplinar, Bourdieu mobilizou o conjunto de saberes disponíveis sobre as diferentes dimensóes do social para a criaçáo de um sistema de conceitos voltado à descrição dos dados da observaçáo e que se apresentasse como uma teoria alternativa, oposta ao "economicismo", para se compreender a ação econômica (BOURDIEU, 2006, p. 14).

Apoiando-se nessa abordagem estrutural, enfatizou as relaçóes que possibilitassem a constituição de redes relacionais duráveis por possibilitar a acumulação de um capital de caráter não econômico, porém utilizável como tal (segundo ele), destinado à acumulaçáo e à reprodução social (BOURDIEU, 2010, p. 68). Tal conceito visava a explicar resultados sociais (logo, coletivos)

25 Consequentemente, a obra bourdieuziana centra-se especificamente nas resultantes das relações conflituosas que ocorrem entre agentes e estruturas, ou seja, nas formas materiais ou simbólicas da violência inerentes à dominação. Ver, para maiores detalhes, Bourdieu (2007, p. 199-25I). 
de "uma miríade de relaçôes historicamente construídas por diferentes indivíduos", fruto do pertencimento a certo grupo ou corpo social, cujo capital específico, de que são detentores cada um de seus membros, eles são capazes de "mobilizar" em determinada intensidade, a partir de suas açóes socialmente diferenciadas.

Capital Social é o conjunto de recursos atuais e potenciais que estão associados à posse de uma rede durável de relações mais ou menos institucionalizadas de interconhecimento e inter-reconhecimento ou, em outros termos, à vinculação a um grupo cujo conjunto de agentes que não somente são dotados de propriedades comuns (passíveis de serem percebidas pelo observador, pelos outros ou por eles mesmos), mas também são unidos por ligações permanentes e úteis. (BOURDIEU, 2010, p. 67).

Consequentemente, capital social pressupóe: a) um conjunto de recursos resultantes da posse ou pertencimento a um grupo ou "corpo" social; b) nesse locus se desenvolvem "relaçôes" com certo nível de institucionalização (logo, envolvendo, em algum grau, certas normas, valores e regras), que imprimem regularidades comportamentais ou cognitivas ao grupo ou "corpo" social, mas que também podem gerar conflitos que pressionam pela sua mudança, explicam seu caráter histórico (logo, evolutivo e temporal) e justificam sua dinâmica relacional; c) essas relações geram interconhecimento e inter-reconhecimento, que reforçam as regularidades comportamentais, tornando-as mais constantes, repetitivas e intensas, logo mais duráveis e permanentes; d) esse interconhecimento e inter-reconhecimento continuamente reforçado cria o "amalgamento grupal" de níveis diferenciados, ou seja, imprime propriedades comuns a cada tipo de grupo, um "habitus" específico (atitudes, concepçôes e disposiçóes) a cada um deles ${ }^{26}$, ou ainda, uma tipologia específica (de açóes comportamentais ou cognitivas) que une (liga) de forma permanente e útil seus participantes, gerando resultados positivos; e) essas ligaçóes, constituídas por "trocas" materiais ou simbólicas (logo, envolvendo compartilhamentos ou açôes cooperativas) criam comportamentos que logicamente supóem certa proximidade (no sentido de frequência, repetitividade ou continuidade) ${ }^{27}$.

26 Esse amalgamento grupal - fruto do interconhecimento e do inter-reconhecimento caracterizados por meio de propriedades comuns a cada grupo (atitudes, comportamentos, modos de expressão, vestimentas, concepções e disposições), definindo seu habitus específico - mostra que Bourdieu também destaca a criação de capital social por meio do conceito de "habitus", análise que faremos mais adiante.

27 Os elementos analisados demonstram que essa formulação, salvo melhor juizo, a mais elaborada das formulações sobre esse conceito, está centrada no "poder" de influenciar ou pressionar para a conquista de vantagens geradoras de predomínio na estrutura social. 
O capital social, relativamente ao campo econômico, e sobretudo se referindo a uma empresa particular, representa "o conjunto de recursos associados [...] à vinculação a um grupo", designa o poder resultante da participação ou pertencimento "a determinados corpos", conjunto de agentes dotados de características comuns que procuram garantir aos seus membros um volume de benefícios ${ }^{28}$. Consequentemente, o conceito reforça sua crítica ao "homo oeconomicus" e ao "individualismo metodológico", próprios do neoclassicismo.

Nesse sentido, o objetivo de Bourdieu é demonstrar que a tomada de decisão internamente à empresa náo é fruto da ação de um indivíduo "autômato" isolado, possuidor de todas as informaçóes relevantes, como é argumentado por aquela vertente teoricamente dominante na economia. A pesquisa sobre o campo de produção e comercialização de casas individuais mostrou-lhe que esse processo decisório é fruto das lutas internas à empresa, visando a privilegiar interesses dos diversos atores detentores de posiçóes na estrutura do capital geral, e da capacidade de esses atores imporem aqueles interesses; logo, de sua influência ou poder decorrente do volume e da estrutura de seu capital específico.

Portanto, a partir da visão do social que antepõe estruturas e agentes, o volume do capital social possuído e mobilizável por um indivíduo emerge como fruto tanto da extensão da rede relacional (desenvolvida por esse agente) ou da difusão dos relacionamentos, concretizada na expansão dos "nós" relacionais "que ele é capaz de mobilizar", quanto do volume do capital "em geral" possuído por esse agente -determinante de sua posição na estrutura de distribuição das posiçóes - no interior do grupo ou do campo a que ele pertence e que define o capital específico do grupo.

Essa interdependência entre o capital social e os capitais possuídos por um agente ou um grupo resulta do inter-reconhecimento ou do estabelecimento do "amalgamento grupal", entendido como o pertencimento ou a

28 Segundo Bourdieu (2004, p. 175), esses "corpos" se manifestam principalmente nas lutas internas à empresa pelo domínio das decisões, que geralmente ocorrem nos momentos de sucessão de comando na empresa, conflitos entre filiais e matriz e tantos outros fatores que podem gerar declínio da confiança na empresa e no valor de seus produtos. Sobre as lutas internas às empresas, ele se refere ao capital "de caráter econômico" (ações), ao capital "de caráter escolar", principalmente quando associado a posições ocupadas na empresa e que exigem determinada formação escolar, e "ao capital social", ligado à participação (pertença) a determinados "corpos". 
vinculação (porém de forma mais intensa), uma vez que supóe o reconhecimento de homogeneidade comportamental (fruto de relaçóes mais ou menos institucionalizadas) indutora do reforço ou do efeito multiplicador da "influência" ou do poder do capital individual ou grupal ${ }^{29}$. Assim, a eficácia das relaçôes constitutivas dessa "espécie" de capital está associada à sua frequência (relaçóes mais ou menos numerosas) e à sua intensidade e/ou compromisso (e mais ou menos ricas) - atributos situados na origem da confiança mútua (BOURDIEU, 2000, p. 14).

Ainda em relação ao campo econômico e referindo-se ao capital social, o autor é explícito ao designá-lo como: "o conjunto de recursos mobilizados (capital financeiro, mas também informação etc.) através de uma rede de relaçôes mais ou menos extensa ou mais ou menos mobilizável que visa a uma vantagem competitiva e garanta aos investimentos rendimentos mais elevados" (BOURDIEU, 2006, p. 265). Nessa expressão, observa-se uma postura explicitamente distinta "das definiçóes posteriormente avançadas na sociologia e economia americana" que, segundo ele, "consideram somente a rede de relaçôes, caracterizadas pela sua extensão e viabilidade". Para Bourdieu, além dessa característica, o conceito deveria abarcar "o volume dos diferentes tipos de capital que permite mobilizar indiretamente [e, como tal, as diferentes vantagens que pode obter]"30 (BOURDIEU, 2006, p. 265).

Porém, ele aprofunda mais essa análise do capital social estendendo seu domínio e sua influência, sobretudo no tocante às empresas dominadas e à "competição pelo poder sobre o poder do Estado". Tal estratégia estabelecida pelas empresas visa a agir influenciando o "poder de regulamentação e os direitos de propriedade" e as "vantagens garantidas por diferentes intervençóes estatais", buscando modificar em seu interesse as regras do jogo em vigor "e fazer valer algumas das suas propriedades susceptíveis de funcionar como capital [...] utilizando o seu capital social para exercer pressóes sobre o Estado”

29 Admitindo diferentes contextos de utilização desse conceito, é possivel destacar o aspecto "peso", ou influên cia, poder sobre o capital detido pelos demais, visando a minimizar distorções ou estabelecer regras favoráveis às vantagens diferenciais. Ver Bourdieu (2000, p. 14) e Bourdieu (2004, p. 173).

30 As afirmações encontradas na nota de rodapé $n^{\circ} 4$ em Bourdieu (2006, p. 265), salvo melhor juizo, exprimem mais a ideia de interferências, fruto da dominação, ou a produção de diferenciais na estrutura social, logo, envolvendo a ideia de mercado como um "campo de lutas" pela manutenção ou ampliação de determinada posição ou participação, coincidente com a visão de Steindl (1983), bem desenvolvida em Possas (1985), e que exprime mais dominação. 
(BOURDIEU, 2006, p. 280). Embora no caso de empresas dominadas esse objetivo dos benefícios seja mais visível, tendo em vista seu interesse individual (mesmo considerando a possibilidade de as empresas dominantes se valerem dessa possibilidade), é inegável que o poder influenciador desse capital se amplia, ampliando seu objetivo aos agentes de maior importância na estrutura social.

Podemos considerar que em Bourdieu (2010, p. 67) encontramos implícita a criaçáo de capital social a partir do conceito de "habitus" (atitudes, comportamentos, modos de expressão, vestimentas, concepçôes e disposiçôes), uma vez que os grupos desenvolvem formas de "ser no mundo", todas compartilhadas ${ }^{31}$ por indivíduos de uma mesma classe. Isto é, são relaçôes construídas a partir de redes relacionais, geradoras de amalgamento grupal, pertencimento ou vinculação entre os agentes; além de criadoras de um envolvimento consciente e conjunto que permite o desenvolvimento participativo de todos, por se sentirem os verdadeiros criadores do sucesso atingido. Nesse aspecto, o autor consegue dar maior concretude à sua forma distinta de explicação do conceito, ou seja, ir além da ideia de que o volume de capital social que um indivíduo possui está associado somente à extensão dos relacionamentos que ele é capaz de mobilizar ${ }^{32}$. Uma vez que agente e estrutura são aspectos do social antepostos por Bourdieu, ele adiciona a relação com a estrutura introduzindo o volume dos diferentes capitais, próprios de cada um dos agentes aos quais estiver unido, visando à obtenção de algum tipo de “dominação" (BOURDIEU, 2010, p. 68).

Não é difícil compreender que Bourdieu procura destacar o "poder" como atributo explicativo da relevância do conceito. Porém, ele também deixa claro que é o grupo quem deve "circunscrever a concorrência interna em limites além dos quais ela comprometeria a acumulação do capital que funda o grupo". Esse "corpo", em razão da possibilidade de comportamentos oportunistas ou de "falhas individuais [...] impóe consequentemente a todos os membros

31 O que também ressalta atributos como: confiança, pertencimento e compartilhamento, próprios de interações - numerosas, duráveis, ricas, extensas e mobilizáveis -, como ele mesmo destaca enfaticamente referindo-se aos atributos desses interconhecimentos e inter-reconhecimentos.

32 O capital social para determinado grupo impulsiona os mecanismos de sua reprodução, cuja origem associa-se tanto às instituições destinadas à facilitação das relações de trocas entre indivíduos ligados a esse grupo, quanto ao trabalho de sociabilização necessário à aceleração do volume das trocas e ao inter-reconhecimento, fundamental para a intensificação do amalgamento grupal. 
do grupo, sem distinção, a caução do capital coletivamente possuído", ou seja, o "descrédito que pode ser acarretado pela conduta de qualquer um deles" (BOURDIEU, 2010, p. 69). Novamente, surgem as relaçóes de "amalgamento grupal" (interconhecimento e inter-reconhecimento) desenvolvidas internamente ao grupo, como as propiciadoras do poder que este, ou algum representante designado pelo grupo, pode exercer sobre ele.

$\mathrm{Na}$ tentativa de integrar o simbólico ao tema do desenvolvimento territorial, inicialmente afirmamos que as análises anteriores mostram que ambos os autores primam por reconhecer o capital social como um ativo ${ }^{33}$ (no sentido econômico-contábil), passível, portanto, de acumulação e reprodução. Os autores divergem em relaçáo à amplitude do conceito ou quanto à dimensão em que ele é analisado. Bourdieu ressalta aspectos econômicos, culturais e até simbólicos, enquanto Putnam, por adotar um enfoque eminentemente quantitativo, enfrenta o dilema de tratar os diferentes tipos de associaçóes, cujas particularidades são muitas vezes ignoradas (FREY, 2003), ou tratar atividades próprias a determinados indivíduos como propriedades gerais e permanentes (BOURDIEU, 1996).

Se, de um lado, as características do capital social em Putnam se referem unicamente ao caráter institucional - "suas instituiçóes e governos" -, propiciador de integração grupal, mesmo considerando a possibilidade de mecanismos destinados a coibir comportamentos negativos, em Bourdieu elas assumem pelo menos três aspectos diferentes: o caráter instrumental gerador de benefícios; o caráter simbólico representado pelo poder ${ }^{34}$, associado a este capital e por "uma propriedade de qualquer tipo de capital" (BOURDIEU, 1996 p. 107); e o caráter intrínseco ao habitus, que reforçaria os aspectos instrumentais e de poder anteriores. O objetivo fundamental de Putnam é o de explicar os diferentes resultados obtidos por governos democráticos de

33 No entanto, há que se observar que, se o capital econômico possui caracteristicas de bem privado - rivalidade real entre seus detentores -, o capital social, por possuir um caráter não econômico ou de não rivalidade, assume aspectos de bem público - sua acumulação e reprodução somente são possiveis a partir do interconhecimento e do inter-reconhecimento, próprios de ambientes comunitários (embora seja possivel a presença de "free Rider").

34 Bourdieu atribui ao simbólico uma forma de capital, "crédito [...] firmado nas inúmeras operações [...] pelas quais os agentes conferem a uma pessoa - ou a um objeto - os próprios poderes que eles lhes reconhecem [...] em particular, em tudo o que faz a simbólica do poder, trono, cetros e coroas" (BOURDIEU, 2009, p. 188) e que transforma o capital simbólico naqueles capitais econômico e cultural, e até o social (grifo meu), reconhecido pelos outros em um determinado campo social. Ver mais detalhes em Ortega (2008, p. 60). 
territórios detentores de recursos similares, porém associando-os às suas instituiçôes e governos, uma vez que propiciam elevados níveis de capital social e confiança, ambos difundidos genericamente por meio da confiança recíproca.

Com relação aos fatores criadores do capital social, salvo melhor juízo, Putnam e Bourdieu muito se aproximam, pois se Putnam assume por engajamento cívico um elevado estoque de capital social de onde seriam acionados os mecanismos produtores de melhorias no desempenho das instituiçóes e governos locais, Bourdieu enfatiza "o peso ou a influência", frutos de "trunfos" ou "fatores diferenciais de sucesso" (BOURDIEU, 2006, p. 264). Destes surgiriam posiçóes mais elevadas na estrutura social, configurando em ambos os casos uma visão eminentemente instrumentalista. Entretanto, quando esse peso reflete uma ingerência conflitual ou a competição por posiçôes na estrutura do campo, Bourdieu supera as afirmaçóes de Putnam. A ideia de conflito, generalizada em sua obra, expressa o realismo dos fatos, debates e disputas que ocorrem internamente aos territórios quanto à imposição de interesses específicos de agentes individuais ou grupais. Nesse sentido, embora Putnam pouco avance (ORTEGA, 2008), não podemos deixar de reconhecer sua relevância.

Referindo-se ao campo da grande organização produtiva, Bourdieu explicita mais incisivamente os conflitos quando se refere às lutas pelo poder interno a elas, visando ao privilégio ou ao controle sobre os interesses (ou até à imposição dos interesses) dos diversos atores, detentores de posições na estrutura de distribuição do capital total da empresa. Assim, ao afirmar que esse poder é fruto da extensão dos "nós" relacionais que o agente é capaz de mobilizar, Bourdieu não se distingue de Putnam e permanece no âmbito da crítica instrumentalista, embora também enfatize que esse poder ou o peso de um agente se baseia no volume e na estrutura de seu capital próprio nas suas diversas espécies (BOURDIEU, 2006, p. 264).

Aprofundando seu argumento, ele também postula que a definição da posição de um agente no interior do grupo ou do campo ao qual ele pertence é também determinada por esse capital, fonte da definiçáo do capital específico do grupo e fundamento da introdução da estrutura social no conceito de capital social ${ }^{35}$. No entanto, deve se enfatizar na discussão sobre o desenvolvimento territorial que, além do poder econômico presente, associado à

35 Salvo melhor entendimento, também podemos avançar na ideia de que é nesse momento que ocorre a introdução dos aspectos simbólicos incrustados nos comportamentos dos agentes presentes em determinado território. 
distribuição estrutural desigual, o elemento de maior significância estaria no poder simbólico representado pela influência de cada um dos participantes visando ao amalgamento relacional necessário à construção de projetos pactuados.

$\mathrm{Na}$ abordagem de Bourdieu envolvendo o desenvolvimento na perspectiva local/territorial, a existência de um poder simbólico intrínseco ao capital social, transfigurado em poder influenciador dos agentes envolvidos nos territórios, incrustado em relaçóes sociais produtoras do "amalgamento grupal", é o aspecto essencial responsável pela confiança, pela reciprocidade e pelo reconhecimento ${ }^{36}$, embora sejam relações que não excluem seu caráter conflituoso. Salvo melhor juízo, isso sugere apenas a disposição coletiva, internalizada por todo o campo, de um envolvimento em açóes voltadas ao consenso coletivo.

A origem desse comportamento compartilhado se encontra na crença ou no reconhecimento da confiança em um indivíduo a partir da confiabilidade que todos os participantes depositam nele. Explicando melhor, o aspecto simbólico presente nesse poder encontra-se em "reconhecimento, crédito, aceitaçáo ou confirmaçáo que aquele, que lhe está sujeito, diz ou dá àquele que o exerce, a fé (fides, ou auctoritas) que uma pessoa confia a outra ou a um grupo pondo neles a sua confiança", isto é, "um poder que existe porque aquele que lhe está sujeito crê (um crédito ou carisma) que ele existe”. (BOURDIEU, 2009, p. 188).

\section{Considerações finais}

Existem algumas semelhanças determinantes de certa proximidade entre ambos os autores no tratamento teórico-interpretativo do capital social, principalmente naquilo que se refere ao significado do conceito. Entretanto, naqueles aspectos referentes à extensão de sua abordagem, as divergências mostram-se mais profundas relativamente às poucas convergências. Com relação aos aspectos simbólicos, Bourdieu apresenta interpretaçóes de maior profundidade, dando destaque tanto ao lado da crença como ao do poder que ela permite exercer.

36 Na verdade, a grande força de suas reflexões sobre a questão do reconhecimento está em mostrar a imbricação entre o conhecimento e o reconhecimento ou, como em Caillé (2008, p. 154), mostrar "como se entrecruzame se interpenetram as categorias de pensamento, as formas de classificação que permitem pensar e conhecer o mundo, e aquelas que valorizam tanto as categorias cognitivas como as axiológicas". 
A melhor coordenação e a maior cooperação, frutos de redes de relacionamento, de normas e da confiança resultantes das relaçóes desenvolvidas nas organizações sociais, são a grande contribuição de Putnam. No entanto, em Bourdieu a confiança e a reciprocidade também podem emergir do "amalgamento grupal”, que outra coisa não é senão a intensificação do comportamento relacional de um indivíduo ou grupo, resultante do interconhecimento e do inter-reconhecimento das ligaçôes permanentes e úteis.

Por fim, a análise que inter-relaciona os agentes e suas lutas por ascenderem na estrutura social mostra-se mais de acordo com a realidade enfrentada tanto por trabalhadores, quanto por micro e pequenos empresários urbanos e rurais, principalmente aqueles de regióes para as quais as teorias de desenvolvimento centradas na perspectiva territorial e envolvendo pactos sociais construídos "desde baixo" - logo, os territórios como elementos de confluências, mas também de conflito de diversos interesses - , são as mais adequadas para utilização.

Nessa perspectiva, a análise de Bourdieu, seja por reconhecer e tratar o conflito de interesses, ou por também servir como elemento explicativo e justificador de comportamentos simbólicos, também carregados de profunda correlaçáo cultural e econômica, deveria merecer maior esforço de análise interdisciplinar, de modo a proporcionar interpretaçóes mais consistentes e propiciadoras de diálogos que envolvam pensamentos e escolas diversas, mas com profunda visão de interconexão.

\section{Referências}

AMARAL FILHO, J. do. A endogeneização no desenvolvimento econômico regional e local. Planejamento e Políticas Públicas, Brasília. n. 23, p. 261-286, jun. 2001.

BECATTINI, G. The Marshallian Industrial Districts as a Socio-Economic Concept. In: PYKE, F; BECATTINI, G.; SENGENBERGER, W. (Ed.). Industrial Districts and Inter-Firms Cooperation in Italy. Geneve: International Institute for Labor and Studies, 1990.

Del distrito industrial marshalliano a la "teoría del distrito" contemporánea: una breve reconstrucción crítica. Investigaciones Regionales, n. 1, p. 9-32, 2002a.

Os distritos industriais na Itália. In: COCCO, G.; URANI, A.; GALVÃO, A. P. (Org.).

Empresários e empregos nos novos territórios produtivos: o caso da Terceira Itália. Rio de Janeiro: DP\&A, 2002b. 
BENKO, G. Economia, espaço e globalizaçáo na aurora do século XXI. São Paulo, SP: Hucitec/ Anablume, 2002.

; LIPIETZ, A. (Org.). As regióes ganhadoras. Distritos e redes: os novos paradigmas da geografia econômica. Oeiras, Portugal: Celta, 1992.

BOURDIEU, P. The forms of Capital. In: RICHARDSON, J. G. (Org.). Handbook of theory and research for the sociology of education. Nova Iorque: Greenwood, 1985. p. 241-58.

Razóes práticas: sobre a teoria da ação. Campinas, SP: Papirus, 1996.

Coisas ditas. São Paulo, SP: Brasiliense, 2004.

O campo econômico. Política e Sociedade, Florianópolis, n. 6, p. 15-57, abr. 2005.

As estruturas sociais da economia. Porto, PT: Campo das Letras, 2006.

Meditaçóes Pascalianas. Rio de Janeiro, RJ: Bertrand Brasil, 2007.

A economia das trocas simbólicas. São Paulo, SP: Perspectiva, 2009.

Escritos de educaçáo. Rio de Janeiro, RJ: Vozes, 2010.

; WACQUANT, L. Una invitation a la sociología reflexiva. Buenos Aires: Siglo XXI, 2008.

BOYER, R. L'Après-consensus de Washington: Institutionnaliste et Systémique. L'Année de La Regulation, Paris, Presses de Sciences-Po, n 5, p. 13-56, 2001.

BRANDÃO, C. A. Territórios com classes sociais, conflitos, decisão e poder. In: ORTEGA, A. C.; ALMEIDA FILHO, N. (Org.). Desenvolvimento territorial, segurança alimentar e economia solidária. Campinas, SP: Alínea, 2007.

CAILlÉ, A. Reconhecimento e Sociologia. Revista Brasileira de Ciências Sociais, São Paulo, v. 23 , n. 66 , p.151-163, fev. 2008.

COLEMAN, J. Foundations of Social Theory. Cambridge: Cambridge University Press MA, 1990.

FREY, K. Capital social, comunidade e democracia. Política e Sociedade, Florianópolis, n. 2, p. $175-187$, abr. 2003.

GAROFOLI, G. O exemplo italiano. Ensaios FEE, Porto Alegre, v. 14, n. 1, p. 49-75, 1993.

HAESBAERT, R. O mito da desterritorializaçáo: do "fim dos territórios" à multiterritorialidade. Rio de Janeiro: Bertrand Brasil, 2006.

LOURY, G. C. A dynamic theory of racial income differences. In: WALLACE, P. A.; LA MONDE, A. M. (Org.). Women, minorities, and employment discrimination. Lexington, MA: Heath, 1977. p. 153-186. 
MARQUES, R. Os trilhos da nova sociologia econômica. In: PEIXOTO, J.; MARQUES, R. (Org.). A nova sociologia econômica. Oeiras, Portugal: Celta, 2003.

MARSHALL, A. Princípios de Economia: tratado introdutório. São Paulo, SP: Abril Cultural, 1983. Coleção Os Economistas, v. 1.

MULS, L. M. Desenvolvimento local, espaço e território: o conceito de capital social e a importância da formação de redes entre organismos e instituiçóes locais. Revista EconomiA, Brasília, DF, v. 9, n. 1, p. 1-21, jan./abr. 2008.

ORTEGA, A. C. Territórios deprimidos: desafios para as políticas de desenvolvimento rural. Campinas, SP: Alínea; Uberlândia, MG: Edufu, 2008.

; ALMEIDA FILHO, N. (Org.). Desenvolvimento territorial, segurança alimentar e economia solidária. Campinas, SP: Alínea, 2007.

PECQUEUR, B. De l'espace fonctionnel à l'espace-territoire. PhD Thesis. UPMF/Grenoble, 1987.

PIORE, M. J.; SABEL, C. F. The second industrial divide: possibilities for prosperity. New York: Basic Books, 1984.

POSSAS, M. L. Estruturas de mercado em oligopólio. São Paulo, SP: HUCITEC, 1985.

PUTNAM, R. Comunidade e Democracia: a experiência da Itália moderna. Rio de Janeiro: Fundação Getúlio Vargas, 2006.

REIS, J. A globalização como metáfora da perplexidade? Os processos geoeconômicos e o "simples" funcionamento dos sistemas complexos. In: SANTOS, B. S. A globalizaçáo e as ciências sociais. São Paulo: Cortez, 2002.

SCHMITZ, H. Eficiência coletiva: caminho de crescimento para a indústria de pequeno porte. Ensaios FEE, Porto Alegre, v. 18, n. 2, p. 164-200, 1997.

SETTON, M. G. J. Uma introdução a Pierre Bourdieu. Revista Cult, n. 128, Ano 11, set. 2008. Disponível em: http://revistacult.uol.com.br/home/2010/03/uma-introducao-a-pierre-bourdieu/

STEINDL, J. Maturidade e estagnaçáo do capitalismo americano. São Paulo, SP: Abril Cultural, 1983. Coleção Os Economistas.

SIISÍÄINEM, M. Two concepts of social capital: Bourdieu vs. Putnam. ISTR four International Conference "The Third Sector: For What and for Whom?". Dublin, Ireland: Trinity College, July 5-8, 2000 .

WHITAKER, J. K. (Ed.). The early economic writings of Alfred Marshall. v. 2. Londres: Mac Millan, 1975. 
Recebido em: 22.08.2012

Aprovado em: 15.04.2013

\section{Territory, endogenous development and social capital at Putnam and Bourdieu}

\section{Abstract}

The study of development should not be restricted to a single theoretical field. Recent studies suggest interaction between economics, history, sociology and other social sciences in the perspective of the territory as social construction based on cooperation and reciprocity, even being conflicting in nature. Many of these prospects assume that building a territory requires the existence of a high "social capital" which enables the establishment of a favorable environment for engaging development. In Putnam, for example, the social capital is an essential aspect for the apprehension of the endogenous character of development. As a critic of this perspective, Bourdieu underscores the need for introducing symbolic aspects for understanding of development as a collective construction of local agents. Although certain proximity between the formulations, especially in the theoretical-interpretive treatment of social capital that refers to its length, can exist, the differences among these authors are not to be disregarded. Interdisciplinary, combining symbolic interpretations, cultural and economic elements are highlighted at Bourdieu's analysis as a facilitator of dialogue involving diverse schools and thoughts, but with profound vision of interconnection.

Keywords: Land. Development. Industrial Districts. Social capital. 